\title{
The evaluation of proliferation ability of cardiomyocytes in heart failure
}

\author{
Mengzi Gao ${ }^{1}$ \\ ${ }^{1}$ Qingdao University, Qingdao, China
}

\begin{abstract}
The proliferation ability of cardiomyocytes is always under a controversial situation, especially under some stress condition such as heart failure disease and external damages. Heat failure (HF) is a complex clinical syndrome that results from left ventricular myocardial dysfunction and contributes to dyspnea, fatigue and fluid retention. The proliferation ability is related to the cell cycles and lot of cell-cycle related genes are involved in the evaluation of proliferation ability of cardiomyocytes. RNA-seq is a quite common technique in evaluate the transcription expression pattern of genes in many studies. Here in our article we analyzed the existing RNA-seq dataset to evaluate the mRNA expression level of several genes which can be indicators of the activity of cell cycles. We found that the cyclin D2 which is a cell cycle activator is upregulated in dilated cardiomyopathy (DCM) disease, indicating that the proliferation ability may be higher in DCM heart. The results throw light on the proliferation research of adult cardiomyocytes.
\end{abstract}

\section{INTRODUCTION}

\subsection{Cardiomyocyte Proliferation}

The pattern of cardiomyocyte proliferation shows significant spatial and temporal differences during heart development. For mouse the proliferation ability is very high during embryonic stage and the ability will decrease after birth. For newborn mouse hearts, they still show regeneration ability until postnatal day 3 under various types of heart damage including apical resection, myocardial infarction and cryoinjury. However, findings in this area are still controversial which is due to the differences in severity of the same injuries and different damage surgeries or post-surgery care.

The reasons that the adult cardiomyocytes show no proliferation ability are that they cannot reentry the cell cycle. It is important to evaluate the proliferation ability by evaluating cell cycle related genes expression level. In other words, the decrease of proliferation is accompanied by the down regulation of necessary cellcycle regulators and upregulation of cell-cycle inhibitors. Table 1 shows the mainly regulators of cell-cycle which can be involved in the regulating cardiomyocytes proliferation ability.

Table 1. Molecules Involved in Regulating Cardiomyocytes Proliferation

\begin{tabular}{|c|c|c|c|}
\hline $\begin{array}{l}\text { Cell-cycle } \\
\text { regulators }\end{array}$ & Molecules & Function in Cardiac Myocyte Proliferation & References \\
\hline \multirow[t]{3}{*}{$\begin{array}{l}\text { Cdk/cyclin } \\
\text { complex }\end{array}$} & $\begin{array}{l}\text { Cyclin } \\
\text { B1/CDC2 }\end{array}$ & $\begin{array}{l}\text { Overexpression of cyclin } \mathrm{B} 1 / \mathrm{CDC} 2 \text { induces adult rat } \mathrm{CMs} \\
\text { division }\end{array}$ & 1 \\
\hline & $\begin{array}{l}\text { Cyclin D1 } \\
\text { Cyclin D2 }\end{array}$ & $\begin{array}{l}\text { Overexpression of cyclin D1 promotes hypertrophic growth } \\
\text { Overexpressing cyclin D2 but not D1 and D } 3 \text { results in persisted } \\
\text { cell-cycle activity and infract regression after injury }\end{array}$ & $\begin{array}{c}2,3 \\
2\end{array}$ \\
\hline & Cyclin A2 & $\begin{array}{l}\text { Constitutive expression of cyclin A2 enhances cardiac myocyte } \\
\text { proliferation resulting in cardiac hyperplasia }\end{array}$ & 4 \\
\hline \multirow[t]{2}{*}{ CDK inhibitors } & $\begin{array}{c}\mathrm{p} 21 \\
(\mathrm{CDKN} 1 \mathrm{~A})\end{array}$ & $\begin{array}{c}\text { Upregulated in postnatal cardiac myocytes, prevents } \\
\text { proliferation }\end{array}$ & 5,6 \\
\hline & $\begin{array}{c}\mathrm{p} 27 \\
(\mathrm{CDKN} 1 \mathrm{~B})\end{array}$ & $\begin{array}{c}\text { Upregulated in postnatal cardiac myocytes, prevents } \\
\text { proliferation }\end{array}$ & 5,6 \\
\hline \multirow{3}{*}{$\begin{array}{l}\text { Upstream } \\
\text { regulators }\end{array}$} & $\mathrm{E} 2 \mathrm{~F} 2$ & Promotes adult cardiac myocyte proliferation & 7,8 \\
\hline & $\begin{array}{l}\mathrm{RB}, \mathrm{p} 107 \\
\mathrm{p} 130\end{array}$ & $\begin{array}{l}\text { Represses cardiac myocyte proliferation by inhibiting E2Fs } \\
\text { expression }\end{array}$ & 6,9 \\
\hline & MEIS1 & Inhibits CM proliferation by activating CDK inhibitors & 10 \\
\hline
\end{tabular}




\subsection{Basic concept of heart failure (HF)}

Heart failure (HF) is a very complicated clinical syndrome of heart disease, and it is often described by many symptoms like fatigue, dyspnea and ankle swelling, which may be accompanied by elevated jugular venous pressure, peripheral oedema and cracked pulmonary.

HF patients are generally divided into two groups, which is depended on the contractile function of the left ventricular myocardium. HF patients with normal left ventricular ejection fraction (LVEF) $(>50 \%)$ is $\underline{\mathrm{HF} \text { with }}$ preserved ejection fraction (HFpEF), while LVEF of HF patients less than $40 \%$ is $\mathrm{HF}$ with reduced ejection fraction (HFrEF). LVEF between $40 \%-49 \%$ is called a 'gray area' which is defined as heart failure with midrange ejection fraction (HFmrEF). Different types of HF have different diagnosis standards, in which HFpEF is more challenging than the HFrEF. ${ }^{11}$

Patients with HF for a long time are diagnosed to have 'chronic HF', in which symptoms remain not changed for at least a month. If the symptoms deteriorate, it can be defined as 'decompensated HF'. ${ }^{11}$

The prevalence of HF in developed countries is approximately $1 \%-2 \%$ of the adult population. While there are over $10 \%$ people with HF in population above 70 years old $^{12}$. What's more, rising rate of diabetes mellitus and hypertension results in the higher rate of patients with HF.

\subsection{Myocardial hypertrophy in HF}

Myocardial hypertrophy is an vital indicator in the process of heart failure and it is also an necessary factor for subsequent heart failure diseases ${ }^{13}$. Under the condition of pressure and volume overload, the heart adapts to increase its output to meet the blood and oxygen demand of body.

Myocardial hypertrophy is a also complicated process in which physiologic, genetic and environmental factors are all involved ${ }^{13}$. Basically, hypertrophy is caused by biomechanical stress such as chronic hypertension, pressure overload and activates multiple parallel. At the cellular level, the biomechanical stress results in overload of pressure and volume. When in pressure overload condition, contractile-proteins will form in parallel and result in width increasing of cardiomyocytes and finally lead to hypertrophy. ${ }^{14}$

In most cases of cardiac hypertrophy, the expression of embryonic genes plays a vital role in the process, embryonic genes including genes for natriuretic and fetal contractile proteins ${ }^{13}$. There are several important factors which can affect the hypertrophic response, such as endothelin, insulin-like growth factor 1 and angiotensin 2. Some peptides are also implicated in hypertrophic response and react as factors mentioned above. For example, peptides stimulate $G$ protein-coupled receptors such as endothelin-1 and angiotensin 2; interleukin-6related cytokines and growth factors. Among these factors, the overexpression of alb-adrenergic receptor will lead to ventricular hypertrophy which shares common signaling pathways in cells with other hypertrophic growth factors, angiotensin II and endothelin-1. ${ }^{13}$

\subsection{Excitation-contraction Coupling (E-C coupling)}

Excitation-contraction coupling (E-C coupling) is the fundamental process which results in contraction of the heart where the calcium is a vital factor in this process. ${ }^{15}$ 16

When action potential is transported to cardiomyocytes, $\mathrm{Ca} 2+$ flows into the cardiomyocytes via voltage-gated calcium channels. Very low calcium concentration from external space triggers much more calcium release from sarcoplasmic reticulum (SR). The combination effect of influx and outflow of calcium causes the increase of calcium concentration in cytosol, and then the calcium binds to the myofilament protein troponin $\mathrm{C}$, leading to the relative movement between myofilaments, which is the cell contraction. Next, the concentration of calcium declines due to many calcium channel transporting calcium to $\mathrm{SR}$, mitochondria, and outer space. Then protein troponin $\mathrm{C}$ releases calcium as the diastole happens. The whole process requires calcium transportation via many proteins including sarcolemma voltage-dependent $\mathrm{Ca} 2+$ channel (LCC), Ryanodine receptor 2 (RyR2), sarcolemma $\mathrm{Na}+/ \mathrm{Ca} 2+$ exchange (NCX), SR Ca2+-ATPase (SEARCA), mitochondrial $\mathrm{Ca} 2+$ uniport (MCU) and sarcolemma Ca2+-ATPase. ${ }^{17}$

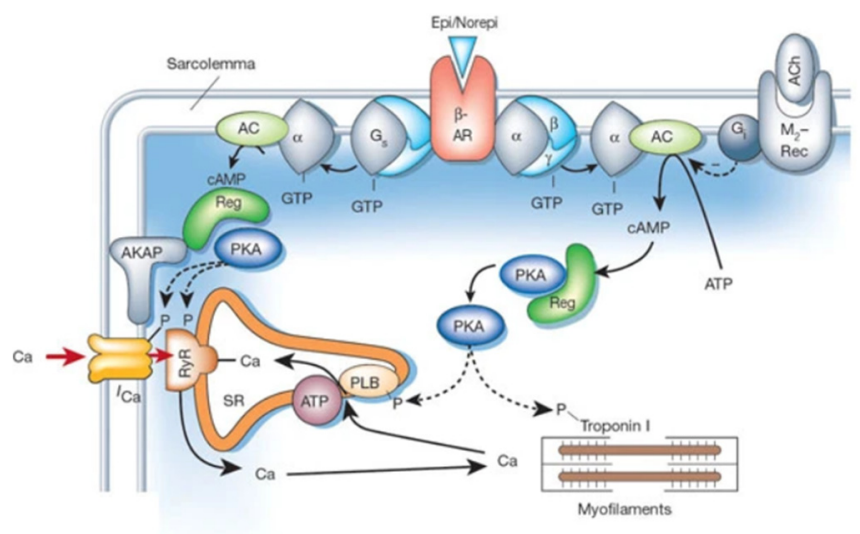

Fig. 1. The model of Excitation-contraction coupling (E-C coupling) in heart. ${ }^{17}$ 
Disorder of calcium in cardiomyocytes causes contractile dysfunction and finally lead to pathophysiological conditions including hypertrophy and heart failure. Keeping a high intracellular calcium concentration will lead to the defective E-C coupling, which can result in pressure overload and higher mass of cardiac muscle, finally hypertrophy ${ }^{13}$.

\section{Changes of E-C coupling related proteins in HF}

During heart failure period, there are huge abnormal expression level changes of E-C coupling related proteins, to some extent could give us the clue to cure the $\mathrm{HF}^{16}$ (Table 2).

As is known that calcium handling alters in $\mathrm{HF}$, and previously studies found that the function of NCX is enhanced, accompanied with the upregulated NCX protein in most HF cases ${ }^{18}$.In HF SR calcium content is depressed, which is supposed to be due to the decline of
SERCA2a expression, and the decrease of the expression eventually leads to the inhibition of SR Ca2+-ATPase function.

In HF diastolic SR calcium leak is enhanced due to the higher open probability of RyR2.We all know that CaMKII plays an important role in RyR2 activity ${ }^{19}$, and the CaMKII-dependent RyR2 phosphorylation activates RyR2 and promotes diastolic SR calcium release, which has the similar role in diastolic SR calcium leak ${ }^{20}$. In HF, CaMKII expression is increased with enhanced RyR2 activation state. 1821

The protein expression level of Na-K-ATPase (NKA) is reduced in $\mathrm{HF}$, but the function of NKA remains normal ${ }^{22}$. Other E-C coupling related proteins also show changes in HF although the expression pattern may not be completely consistent in terms of function.

Protein phospholemman (PLM)expression is reduced but with higher phosphorylated PLM in HF ${ }^{22}$ ${ }^{23}$.Potassium current in HF is also altered, which could modify action potential as well as calcium handling. ${ }^{24}$

Table 2. The summary of changes of E-C coupling key proteins in HF

\begin{tabular}{c|ccc}
\hline \multicolumn{1}{c}{ Trend } & Method & \multicolumn{2}{c}{ Reference } \\
\hline NCX & Increase & Westernblot & Maier LS et al. Cir. Res., 1995 \\
SERCA2a & Decrease & Westernblot & Maier LS et al. Cir. Res., 1995 \\
CaMKII & Increase & Westernblot & Ai X et al. Cir. Res.,2005 \\
Na-K-ATPase & Decrease & Westernblot & $\begin{array}{c}\text { Bossuyt J et al. Cir. } \\
\text { Res.,2005 }\end{array}$ \\
PLM & Decrease & Westernblot & Bossuyt J et al. Cir. \\
& & & Res.,2005 \\
\hline
\end{tabular}

\section{Changes of cell cycle related proteins in human dilated cardiomyopathy (DCM)}

Dilated cardiomyopathy (DCM) is one of the diseases which can result in the HF and here we used the dataset whose GSE number is GSE116250 in which left ventricles from 37 DCM patients and 14 normal human donors were collected ${ }^{25}$. Then the bulk RNA-seq was performed and the analyzed data was acquired from the research.

As we all know, the proteins related to cell cycles were very important in evaluating the proliferation ability of cardiomyocytes. So here we showed the related genes transcriptional expression level in the two groups.

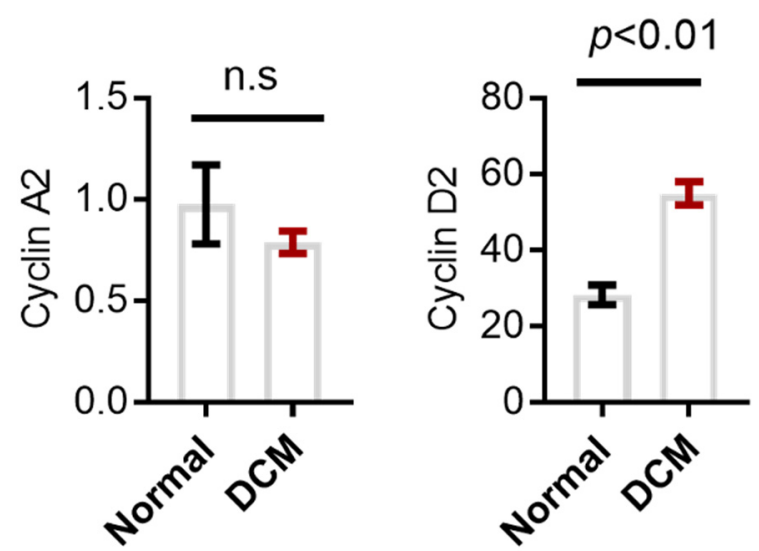

Fig. 2. The mRNA expression level of Cyclin A2 and Cyclin D2 

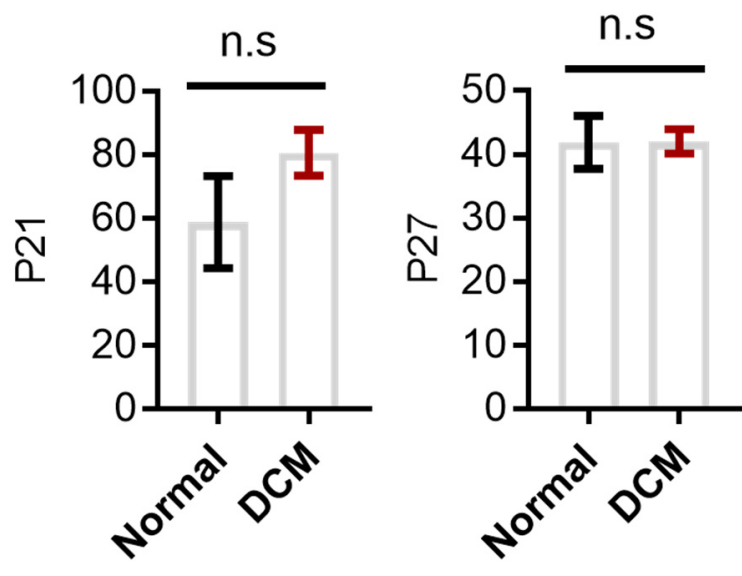

Fig 3. The mRNA expression level of $\mathrm{P} 21$ and $\mathrm{P} 27$

As we know that cyclin A2 and cyclin D2 are all cellcycle activators and several attempts were made by increasing them to restore the proliferation ability of adult cardiomyocytes. We analyzed the dataset and found that cyclin D2 is significantly increased with no obvious changes to cyclin $\mathrm{A} 2$, which indicates that the cell-cycle activity of cardiomyocytes in DCM may show a higher activity than those from normal heart (Figure 2).

We also evaluate the negative regulators of cellcycle-P21 and P27, and the results in Figure 3 show that both P21 and P27 show no changes in mRNA expression level between DCM and normal hearts. The results also support that the cell-cycle activity of cardiomyocytes in DCM may show a higher activity than those from normal heart.

\section{Conclusion}

In this article, we reviewed that some cell cycle regulators were involved in the cell-cycle activity of cardiomyocytes and summarized the characteristic of HF which is a vital disease posting serious threaten on public health. Our research focused on the proliferation of cardiomyocytes under HF conditions by analyzing the existing RNA-seq dataset.

After analyzing the cyclin A2 and cyclin D2, both cell-cycle activator, and P21 and P27, both negative regulators of cell-cycle, we found that the cyclinD2 is significantly upregulated in DCM hearts while the P21 and P27 show no changes at all in the groups. The results give us some clue that cardiomyocytes in DCM condition may have a higher possibility to reentry the cell-cycle and make the cell have the regeneration ability.

Of course, our study only used the RNA-seq data to show the mRNA expression level changes of these genes and the proteins changes are still unknown, so this is also one possibility that the translational expression pattern is not consistent with mRNA expression pattern.

Also, we just evaluate some representative cell-cycle regulators and there are also many of them still not been checked. What's more, in addition to CDK related genes, many cell-cycle regulators such as noncoding RNA, developmental gene programs and Cell-cell interactions also need to be evaluated.

Heart failure is a complicated disease and has a significant threat to human health, and it is important to have a deep investigation to the underlying mechanism. E-C coupling is the fundamental mechanism of the normal function of cardiomyocytes, it would be abnormal in heart failure which results from the altered expression level of key proteins in the process. However, there are lot of proteins which have a different expression level pattern when heart failure happens, and the key factors leading to the disease are still unknown.

As far as our study can see, the cardiomyocytes may have a higher possibility in regeneration, which I think can be interpreted as a feedback of heart to protect itself from HF disease. Of course, the regeneration trend in HF condition may be good for hearts while the outcoming is not always as it seems. However, it encourages us to have a deep insight into the heart proliferation and regeneration in a new view in the future study.

\section{References}

1. Bicknell KA, Coxon $\mathrm{CH}$ and Brooks G. Forced expression of the cyclin B1-CDC2 complex induces proliferation in adult rat cardiomyocytes. Biochem $J$. 2004;382:411-6.

2. Pasumarthi KB, Nakajima H, Nakajima HO, Soonpaa MH and Field LJ. Targeted expression of cyclin D2 results in cardiomyocyte DNA synthesis and infarct regression in transgenic mice. Circ Res. 2005;96:110-8.

3. Soonpaa MH, Koh GY, Pajak L, Jing S, Wang H, Franklin MT, Kim KK and Field LJ. Cyclin D1 overexpression promotes cardiomyocyte DNA synthesis and multinucleation in transgenic mice. $J$ Clin Invest. 1997;99:2644-54.

4. Chaudhry HW, Dashoush NH, Tang H, Zhang L, Wang X, Wu EX and Wolgemuth DJ. Cyclin A2 mediates cardiomyocyte mitosis in the postmitotic myocardium. J Biol Chem. 2004;279:35858-66.

5. Foglia MJ and Poss KD. Building and re-building the heart by cardiomyocyte proliferation. Development. 2016;143:729-40.

6. Flink IL, Oana S, Maitra N, Bahl JJ and Morkin E. Changes in E2F complexes containing retinoblastoma protein family members and increased cyclin-dependent kinase inhibitor activities during terminal differentiation of cardiomyocytes. J Mol Cell Cardiol. 1998;30:56378.

7. Ebelt H, Zhang Y, Kampke A, Xu J, Schlitt A, Buerke M, Muller-Werdan U, Werdan K and Braun T. E2F2 expression induces proliferation of terminally differentiated cardiomyocytes in vivo. Cardiovasc Res. 2008;80:219-26.

8. Ebelt H, Hufnagel N, Neuhaus P, Neuhaus H, Gajawada P, Simm A, Muller-Werdan U, Werdan K and Braun T. Divergent siblings: E2F2 and E2F4 but 
not E2F1 and E2F3 induce DNA synthesis in cardiomyocytes without activation of apoptosis. Circ Res. 2005;96:509-17.

9. MacLellan WR, Garcia A, Oh H, Frenkel P, Jordan MC, Roos KP and Schneider MD. Overlapping roles of pocket proteins in the myocardium are unmasked by germ line deletion of p130 plus heart-specific deletion of Rb. Mol Cell Biol. 2005;25:2486-97.

10. Mahmoud AI, Kocabas F, Muralidhar SA, Kimura W, Koura AS, Thet S, Porrello ER and Sadek HA. Meis1 regulates postnatal cardiomyocyte cell cycle arrest. Nature. 2013;497:249-253.

11. Snipelisky D, Chaudhry S-P and Stewart GC. The many faces of heart failure. Cardiac electrophysiology clinics. 2019;11:11-20.

12. Ponikowski P, Voors AA, Anker SD, Bueno H, Cleland JG, Coats AJ, Falk V, González-Juanatey JR, Harjola VP and Jankowska EA. 2016 ESC Guidelines for the diagnosis and treatment of acute and chronic heart failure: The Task Force for the diagnosis and treatment of acute and chronic heart failure of the European Society of Cardiology (ESC). Developed with the special contribution of the Heart Failure Association (HFA) of the ESC. European journal of heart failure. 2016;18:891-975.

13. Hunter JJ and Chien KR. Signaling pathways for cardiac hypertrophy and failure. New England Journal of Medicine. 1999;341:1276-1283.

14. Baartscheer A, Schumacher C, Belterman C, Coronel R and Fiolet J. [Na+] i and the driving force of the $\mathrm{Na}+/ \mathrm{Ca} 2+$-exchanger in heart failure. Cardiovascular research. 2003;57:986-995.

15. Eisner DA, Caldwell JL, Kistamás $\mathrm{K}$ and Trafford AW. Calcium and excitation-contraction coupling in the heart. Circulation research. 2017;121:181-195.

16. Bers DM. Altered cardiac myocyte Ca regulation in heart failure. Physiology. 2006;21:380-387.

17. Bers DM. Cardiac excitation-contraction coupling. Nature. 2002;415:198.

18. Maier LS, Zhang T, Chen L, DeSantiago J, Brown $\mathrm{JH}$ and Bers DM. Transgenic CaMKIISC overexpression uniquely alters cardiac myocyte $\mathrm{Ca} 2+$ handling: reduced SR Ca2 + load and activated $\mathrm{SR} \mathrm{Ca} 2+$ release. Circulation research. 2003;92:904-911.

19. Ai X, Curran JW, Shannon TR, Bers DM and Pogwizd SM. Ca2+/calmodulin-dependent protein kinase modulates cardiac ryanodine receptor phosphorylation and sarcoplasmic reticulum $\mathrm{Ca} 2+$ leak in heart failure. Circulation research. 2005;97:1314-1322.

20. Jiang MT, Lokuta AJ, Farrell EF, Wolff MR, Haworth RA and Valdivia $\mathrm{HcH}$. Abnormal $\mathrm{Ca} 2+$ release, but normal ryanodine receptors, in canine and human heart failure. Circulation research. 2002;91:1015-1022.

21. Bers DM. Macromolecular complexes regulating cardiac ryanodine receptor function. Journal of molecular and cellular cardiology. 2004;37:417429.

22. Bossuyt J, Ai X, Moorman R, Pogwizd S and Bers D. Altered phospholemman (PLM) expression and phosphorylation in a non-ischemic, arrhythmogenic rabbit heart failure model. Circ Res. 2005;97:558565.

23. Sweadner KJ and Rael E. The FXYD gene family of small ion transport regulators or channels: cDNA sequence, protein signature sequence, and expression. Genomics. 2000;68:41-56.

24. Sah R, Ramirez RJ, Oudit GY, Gidrewicz D, Trivieri MG, Zobel C and Backx PH. Regulation of cardiac excitation-contraction coupling by action potential repolarization: role of the transient outward potassium current (Ito). The Journal of physiology. 2003;546:5-18.

25. Sweet ME, Cocciolo A, Slavov D, Jones KL, Sweet JR, Graw SL, Reece TB, Ambardekar AV, Bristow MR, Mestroni L and Taylor MRG. Transcriptome analysis of human heart failure reveals dysregulated cell adhesion in dilated cardiomyopathy and activated immune pathways in ischemic heart failure. BMC Genomics. 2018;19:812. 